\title{
Size Effect of Copper Precipitation Particles on Electrochemical Nanoscopic Galvanic Behavior in Cu-Added Ultra Low Carbon Steel
}

\author{
Toshihei Misawa ${ }^{1}$, Noriaki Kobayashi ${ }^{1}$, Shin-ichi Komazaki ${ }^{1}$ \\ and Masaaki Sugiyama ${ }^{2}$ \\ ${ }^{1}$ Department of Materials Science and Engineering, Muroran Institute of Technology, Muroran 050-8585, Japan \\ ${ }^{2}$ Advanced Technology Research Laboratories, Nippon Steel Corporation, Futtsu 293-8511, Japan
}

\begin{abstract}
Electrochemical polarization measurements were applied to $\mathrm{Cu}$-added ultra low carbon steels aged at $773 \mathrm{~K}$ for duration ranging from $9 \times 10$ to $5 \times 10^{6} \mathrm{~s}$ to investigate size effect of copper precipitation particles on passivation of the steel. The anodic polarization curve measurements in $0.5 \mathrm{kmol} / \mathrm{m}^{3} \mathrm{H}_{2} \mathrm{SO}_{4}$ solution revealed that the passive current density $I_{\text {pass }}$ showed almost no variation until the aging process reached the overaged stage in which the Vickers hardness of the steel began to decrease. Thereafter, the $I_{\text {pass }}$ increased monotonously with increasing aging time in the overaged stage. This increase in $I_{\text {pass }}$ due to aging was considered to result from the preferential anodic dissolution of grown copper particles. Thus, the corrosion resistance of the $\mathrm{Cu}$-added ultra low carbon steel scarcely deteriorated even if the size of copper particles increased with aging time before the maximum hardness was reached. These results reflected that there was a critical nanometer size of copper particles as a nanoscopic galvanic action beyond which a good protective passive film could not be formed.
\end{abstract}

(Received February 15, 2002; Accepted April 15, 2002)

Keywords: copper added ultra low carbon steel, copper particles, nanoscopic galvanic action, electrochemical polarization measurement, critical size, passivation, passive film

\section{Introduction}

Ultra low carbon steels of $\mathrm{Cu}$-added precipitation hardening type with interstitial free matrix have recently received particular attention as structural steels ranging from thin sheets to thick plates because of their excellent strength/ductility balance. ${ }^{1,2)}$ This balance derives from quite fine copper precipitation particles, which are formed during aging subsequent to the solution heat treatment and dispersed uniformly in the matrix. It is very important to understand the precipitation behavior of copper particles because the mechanical properties of the steels, such as a tensile strength and fatigue strength are closely associated with the size of copper particles, namely, the interparticle spacing.

Additionally, it is also essential to make clear the influence of copper particles on the passivation of the steels or characteristics of the passive film, because $\mathrm{Cu}$-added ultra low carbon steels are commonly used as surface treated steel plates. It is known that some precipitates and/or inclusions in steels act as either an anodic or cathodic site in passive state of matrix. In some circumstance, these particles lead to a heterogeneous formation or breakdown of passive film, resulting in environmental degradations, such as a pitting corrosion, stress corrosion cracking and hydrogen induced embrittlement.

In this study, in order to investigate the size effect of copper particles on the passivation of the steels, an anodic polarization curve measurement was applied to the $\mathrm{Cu}$-added ultra low carbon steels, which had undergone thermal aging at $773 \mathrm{~K}$ for duration ranging from $9 \times 10$ to $5 \times 10^{6} \mathrm{~s}$ and had been provided with various types of fine copper particles. The existence of a critical size of copper particles beyond which protective passive films can not be formed was also examined in terms of change in passive current density due to aging.

\section{Experimental Procedure}

\subsection{Material}

The material used in this study was $\mathrm{Cu}$-added ultra low carbon steel. The chemical composition of the steel is given in Table 1. The steel was solution treated at $1373 \mathrm{~K}$ for $1.8 \times 10^{3} \mathrm{~s}$ and subsequently quenched in water. Then, the steel was isothermally aged at $773 \mathrm{~K}$ for duration ranging from $9 \times 10$ to $5 \times 10^{6} \mathrm{~s}$.

After the thermal aging, each steel was subjected to Vickers hardness measurement under a load of $4.9 \mathrm{~N}$ at room temperature. The microstructure of the aged steels was observed using a high resolution transmission electron microscope (Hitachi H-8000, $200 \mathrm{kV}$ ).

\subsection{Electrochemical polarization measurement}

The aged steels were cut into a flat sheet (e.g., $10 \times 10 \times$ $\left.t 2 \mathrm{~mm}^{3}\right)$. This flat sheet was connected to a lead wire and then covered with epoxy resin, except for the measurement area of specimens for electrochemical polarization measurements. The measurement surfaces were mechanically polished to a $1-\mu \mathrm{m}$ diamond finish. An anodic polarization curve was measured in a $0.5 \mathrm{kmol} / \mathrm{m}^{3} \mathrm{H}_{2} \mathrm{SO}_{4}$ solution at $298 \mathrm{~K}$ with a typical three-electrode cell. Before performing the measurements, the solution was deaerated with nitrogen gas. The specimens were polarized from $-800 \mathrm{mV}$ (vs. SCE) to anodic direction at $0.33 \mathrm{mV} / \mathrm{s}$ sweep rate after a cathodic polarization $\left(-10 \mathrm{~A} / \mathrm{m}^{2}, 300 \mathrm{~s}\right)$ for removing oxide films.

Moreover, in order to detect a dissolution of copper particles, Raman spectra were measured on the electrochemical controlled surfaces in $0.5 \mathrm{kmol} / \mathrm{m}^{3} \mathrm{H}_{2} \mathrm{SO}_{4}$ solution using an in-situ micro Raman scattering spectroscope with a micro electrochemical cell. ${ }^{3)}$ 
Table 1 Chemical composition (mass \%) of $\mathrm{Cu}$-added ultra low carbon steel.

\begin{tabular}{|c|c|c|c|c|c|c|c|c|c|}
\hline $\mathrm{C}$ & $\mathrm{Si}$ & $\mathrm{Mn}$ & $\mathrm{P}$ & $\mathrm{S}$ & $\mathrm{Al}$ & $\mathrm{N}$ & $\mathrm{Ti}$ & $\mathrm{Cu}$ & $\mathrm{Ni}$ \\
\hline 0.0027 & 0.01 & 0.09 & 0.01 & 0.005 & 0.02 & 0.0018 & 0.05 & 1.35 & 0.69 \\
\hline
\end{tabular}

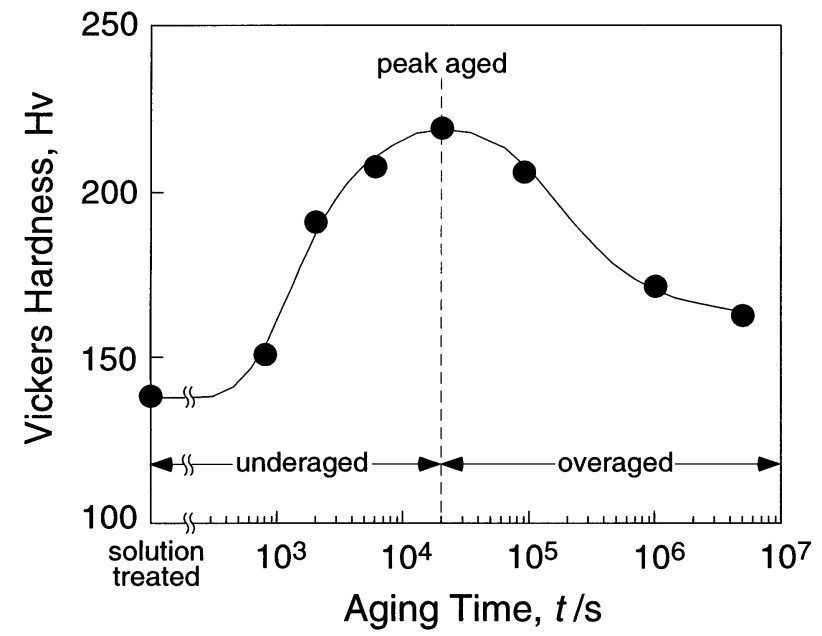

Fig. 1 Change in hardness as a function of aging time.

\section{Results and Discussion}

\subsection{Changes in microstructure and hardness}

The Vickers hardness measured is plotted as a function of aging time in Fig. 1. The maximum hardness is reached after the aging of $2 \times 10^{4} \mathrm{~s}$, and the subsequent hardness monotonously decreases with increasing aging time. Hereafter, the steel, which was thermally aged for $2 \times 10^{4} \mathrm{~s}$ and has maximum hardness, is defined as "peak aged steel". The steels aged for less and more than $2 \times 10^{4} \mathrm{~s}$ are also termed "underaged steel" and "overaged steel", respectively.

A high resolution transmission electron microscope (HRTEM) observation revealed that, as shown in Fig. 2(a), copper-rich clusters, $2-4 \mathrm{~nm}$ in diameter, which were coherent with an $\alpha$-iron matrix, predominantly existed in the peak aged steel. It is apparent that the maximum hardness is attributable to this fine copper-rich cluster. Additionally, as shown in Fig. 2(b), copper particles, $10-15 \mathrm{~nm}$ in diameter were observed to be homogeneously distributed in the matrix of the overaged steel $\left(9 \times 10^{4} \mathrm{~s}\right)$. These particles seemed to be transitional phases represented by twinned $9 \mathrm{R}$ structures, ${ }^{1)}$ which could be transformed to $\varepsilon$-copper (fcc) due to an additional aging. These behavior of age-hardening and copper precipitation observed in this study was in good agreement with those reported in earlier studies. ${ }^{1,2)}$

\subsection{Change in electrochemical properties}

Figure 3 shows typical examples of anodic polarization curves measured on the solution treated, the underaged $(3 \times$ $\left.10^{3} \mathrm{~s}\right)$, the peak aged $\left(2 \times 10^{4} \mathrm{~s}\right)$ and the overaged $\left(6 \times 10^{5} \mathrm{~s}\right)$ steels. Three different potential regions can be clearly identified in each curve: the active, the passive and the transpassive regions. The passive region appears after the current density reaches the critical current density for passivation $I_{\text {crit }}$ at the passivation potential $E_{\mathrm{pp}}$. It can be seen that the passive cur-

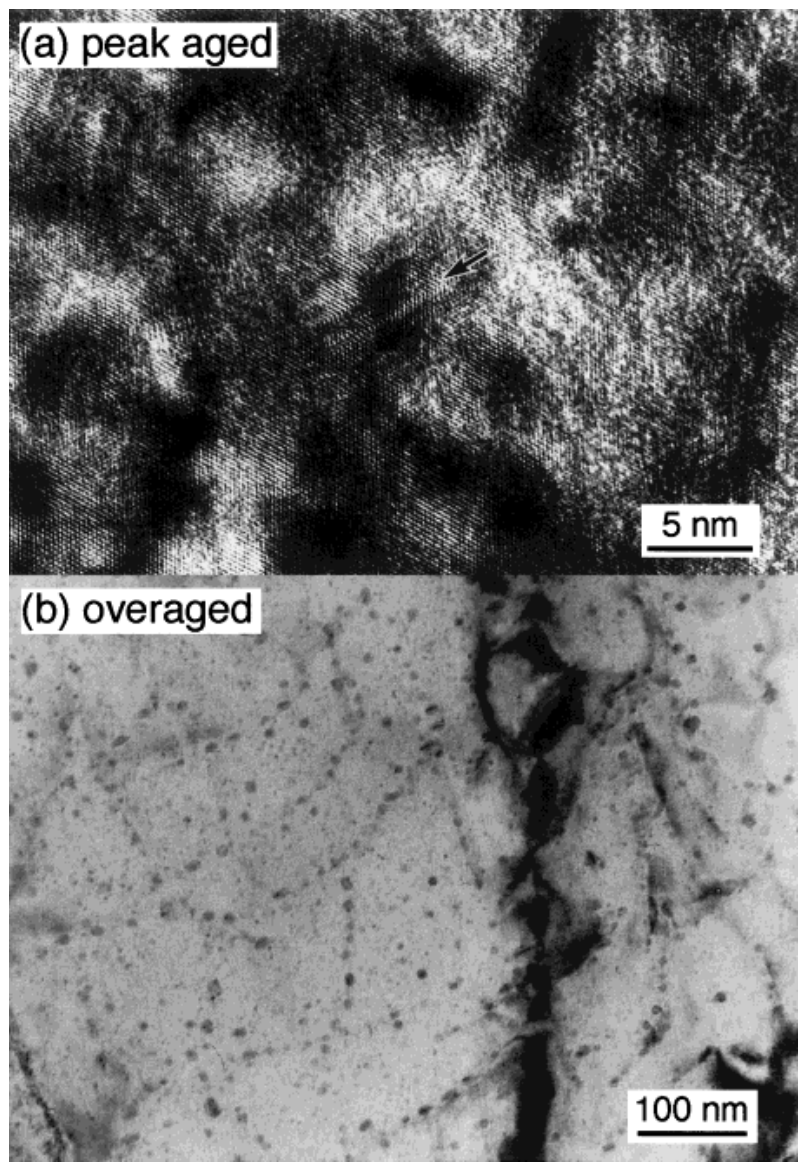

Fig. 2 HRTEM micrographs of aged $\mathrm{Cu}$-added ultra low carbon steels.

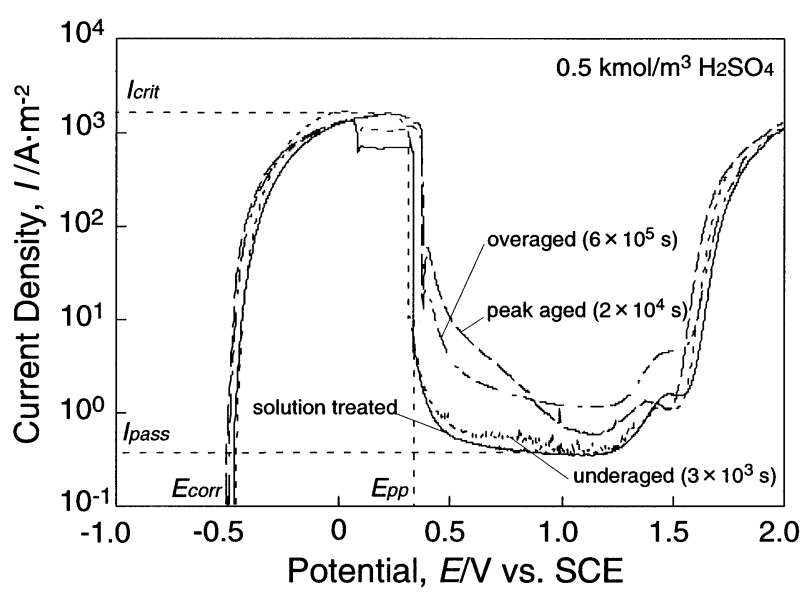

Fig. 3 Typical examples of anodic polarization curves.

rent density $I_{\text {pass }}$, which corresponds to the minimum current density in the passive region, varies with aging time, while the current densities in the other two regions, as well as at the corrosion potential $E_{\text {corr }}$, show almost no variation.

The passive current densities $I_{\text {pass }}$ measured on all the steels are plotted against aging time in Fig. 4. The $I_{\text {pass }}$ shows no 


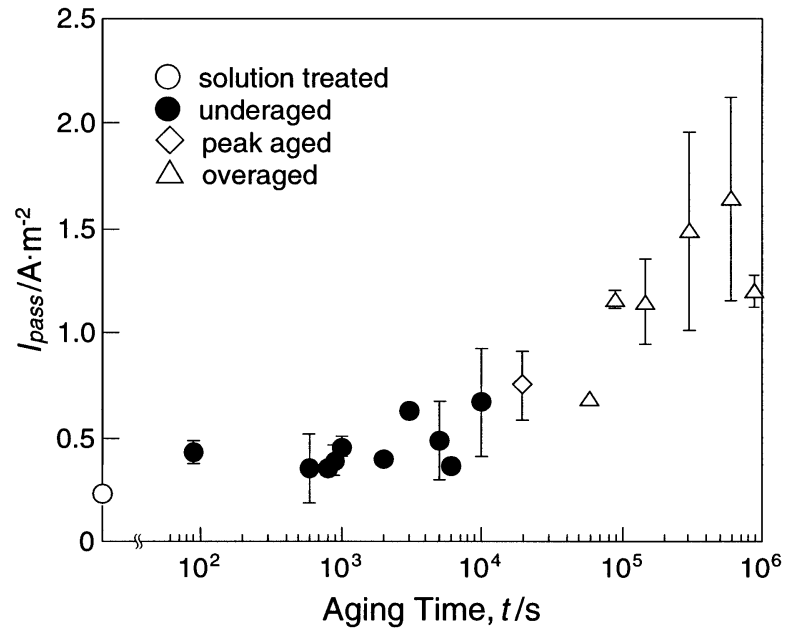

Fig. 4 Passive current density $I_{\text {pass }}$ plotted as a function of aging time.

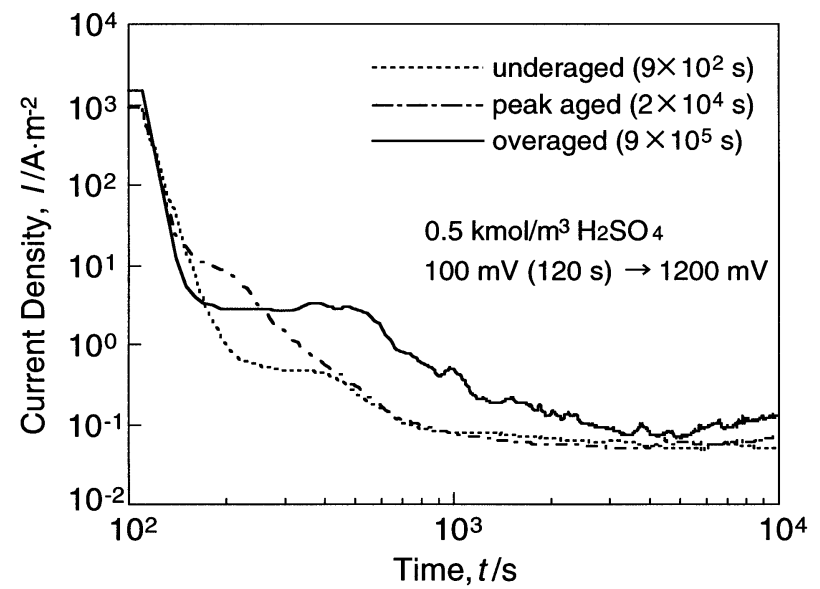

Fig. 5 Typical examples of current decay curves measured in the passivation potential region of $1200 \mathrm{mV}$.

significance change over a range from $9 \times 10$ to $1 \times 10^{4} \mathrm{~s}$, that is, in the region of the underaged stage although some scattering results can be seen. It has a tendency to take off at around the aging time of $(1-2) \times 10^{4} \mathrm{~s}$. Thereafter, in the overaged stage, it is inclined to increase monotonously with increasing aging time. Figure 5 shows examples of current decay curves measured on the underaged $\left(9 \times 10^{2} \mathrm{~s}\right)$, peak aged $\left(2 \times 10^{4} \mathrm{~s}\right)$ and overaged $\left(9 \times 10^{5} \mathrm{~s}\right)$ steels, where the changes in current densities measured in the passivation potential region of $1200 \mathrm{mV}$ after the anodic polarization at $100 \mathrm{mV}$ for $120 \mathrm{~s}$ are plotted as a function of time. The minimum (constant) current densities are reached after about $900 \mathrm{~s}$ in the underaged and peak aged steels, while the overaged steel with grown copper particles requires much longer duration to be minimum value. The above results indicate that the overaged steel is inferior to the underaged and peak aged steels in corrosion resistance in the passive state.

Figure 6 shows the Raman spectra of the underaged $(9 \times$ $\left.10^{2} \mathrm{~s}\right)$ and overaged $\left(9 \times 10^{5} \mathrm{~s}\right)$ steels measured at the corrosion potential $E_{\text {corr }}$ and $400 \mathrm{mV}$ (vs. SCE), which is nearly equivalent to the passivation potential, along with the reference spectra of $0.5 \mathrm{kmol} / \mathrm{m}^{3} \mathrm{H}_{2} \mathrm{SO}_{4}$ and saturated $\mathrm{CuSO}_{4}$ aqueous solutions. As can be seen in this figure, two very large peaks corresponding to the characteristic peak of $\mathrm{H}_{2} \mathrm{SO}_{4}$

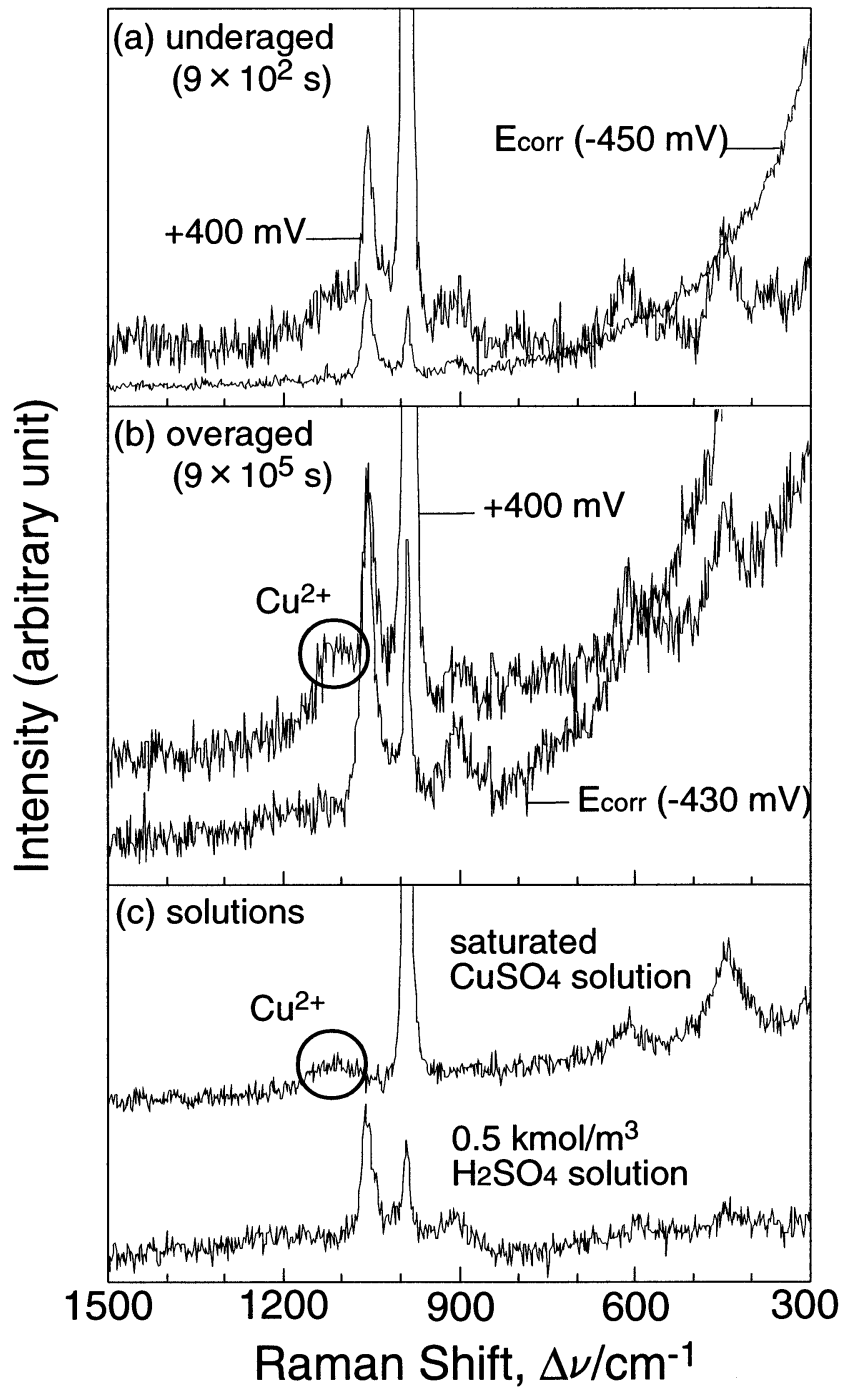

Fig. 6 Changes in in-situ Raman scattering specra with increasing aging time.

appear at about 990 and $1050 \mathrm{~cm}^{-1}$ in all the spectra. Furthermore, the small broad peak attributable to the characteristic peak of $\mathrm{Cu}^{2+}$ aqueous species can be assigned at around $1120 \mathrm{~cm}^{-1}$ in the spectrum of the overaged steel polarized at $400 \mathrm{mV}$. However, in contrast to the overaged steel, the underaged steel of which the passive current density remained quite low does not exhibit such a small broad peak. This characteristic peak of $\mathrm{Cu}^{2+}$ aqueous species seems to reflect the anodic dissolution of copper particles dispersed in the iron matrix, in view of the fact that the passive potential region of the present steel lies in the domains of passivation and corrosion in the E$\mathrm{pH}$ equilibrium diagrams of iron and copper, ${ }^{4,5)}$ respectively.

Based on these results, the above-mentioned increase in passive current density, namely, the degradation of passivation with aging is considered to result from the preferential anodic dissolution of grown copper particles. The size of copper clusters precipitated in the underaged and peak aged steels is presumed to be too small to dissolve as an anodic site. As illustrated by Fig. 7, it is likely that the nanometer size copper clusters are completely covered with the passive film formed on the iron matrix (bridging effect of oxide film) and, consequently, are protected from the aqueous solution. 
underaged steels

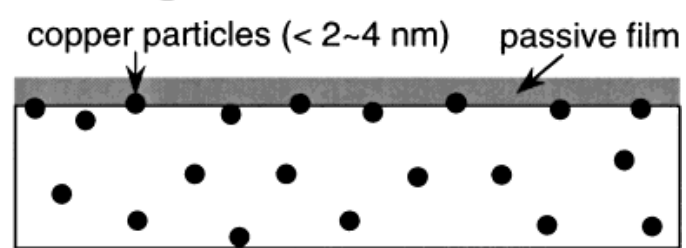

Copper clusters are completely covered with the passive films formed on iron matrix.

growth in size of copper particles via peak aged state

overaged steels

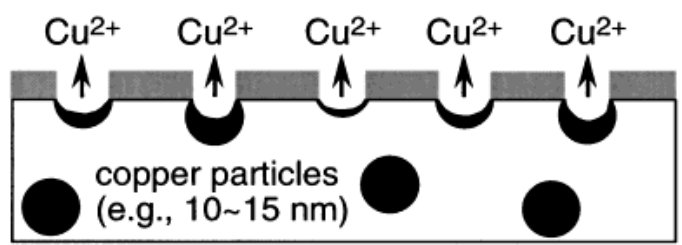

Anodic dissolution of grown copper particles occurs in the passive region of iron matrix.

Fig. 7 Schematic illustration of formation of passive film and dissolution of grown copper particles.

Ishikawa and Yoshimura ${ }^{6)}$ investigated the effect of nanometer size Cr-depleted region on passivity breakdown in ferritic and ferritic/austenitic duplex stainless steels. They reported that the size of the Cr-depleted region must be larger than that of water molecules clustered by hydrogen bond, usually 50-100 molecules large to cause the passivity breakdown, because species in the aqueous bulk solution could not penetrate and react with the $\mathrm{Cr}$-depleted region on the surface if the size of the Cr-depleted region would be smaller than that of the species.

From the results obtained, there is a strong likelihood that a critical nanometer size of copper particles for maintaining a good protective passive film is present. It can be estimated from the results described above (Fig. 4) that the size beyond which a protective passive film can not be formed does not exceed 2-4 nm equivalent to the size of the copper clusters, which precipitate in the peak aged stage. Ishikawa and Yoshimura $^{6)}$ also reported that the size of the Cr-depleted region appeared to be the most critical parameter in inducing the passivity breakdown and that the critical value existed somewhere between 2 and $5 \mathrm{~nm}$. The result obtained from the present study is coincident with their report.

Figure 8 shows the relationship between the Vickers hardness and the passive current density $I_{\text {pass }}$. As mentioned above, the $I_{\text {pass }}$ shows no significant change until the aging process reaches the overaged stage in which the hardness starts to decrease. Thus, the corrosion resistance of the steel scarcely deteriorates even though the size of copper particles increases with aging time before the maximum hardness is reached. On the other hand, the passive current density $I_{\text {pass }}$ tends to increase with decreasing hardness in the overaged stage. As a consequence, it may be concluded that the peak aged steel is most desirable for the present $\mathrm{Cu}$-added ultra low carbon steel from the standpoint of both

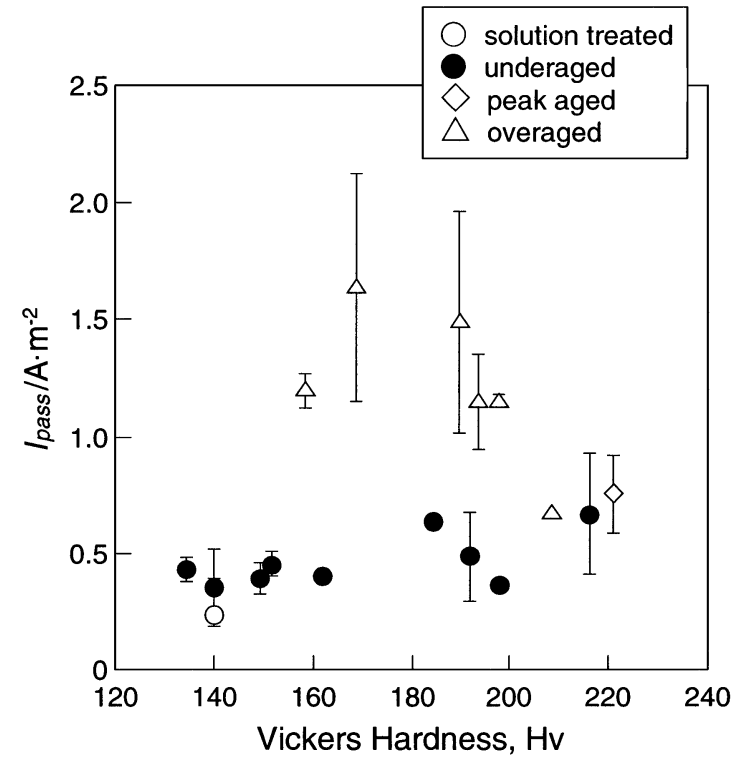

Fig. 8 Relationship between Vickers hardness and passive current density $I_{\text {pass. }}$.

of the strength/ductile balance and the maintenance of good corrosion-resistance in application for surface treated steel plates.

\section{Conclusions}

The passive current density $I_{\text {pass }}$ shows almost no variation until the aging process reaches the overaged stage in which the hardness of the steel begins to decrease. Thus, the corrosion resistance of the $\mathrm{Cu}$-added low carbon steel scarcely deteriorates even if the size of copper precipitation particles increases with aging time before the maximum hardness is reached. On the other hand, the $I_{\text {pass }}$ has a tendency to increase monotonously with decreasing hardness in the overaged stage. This increase in $I_{\text {pass }}$ is caused by the increase in anodic dissolution of grown copper particles as a nanoscopic galvanic action. It can be estimated from the results obtained that a critical nanometer size of copper particles beyond which a good protective passive film can not be maintained does not exceed 2-4 nm equivalent to the size of copper clusters, which predominantly precipitate in the peak aged stage. Additionally, it can be concluded that the peak aged steel is most desirable for the present $\mathrm{Cu}$-added ultra low carbon steel from the standpoint of both of the strength/ductile balance and the good corrosion-resistance maintenance.

\section{REFERENCES}

1) N. Maruyama, M. Sugiyama, T. Hara and H. Tamehiro: Mater. Trans., JIM 40 (1999) 268-277.

2) A. Deschamps, M. Militzer and W. J. Poole: ISIJ Inter. 41 (2001) 196205.

3) H. Tanabe, T. Shibuya, N. Kobayashi and T. Misawa: ISIJ Inter. 37 (1997) 278-282.

4) M. Pourbaix: Atlas of Electrochemical Equilibria in Aqueous Solutions, (Pergamon Press, 1966) pp. 307-321.

5) M. Pourbaix: Atlas of Electrochemical Equilibria in Aqueous Solutions, (Pergamon Press, 1966) pp. 384-392.

6) Y. Ishikawa and T. Yoshimura: Mater. Sci. Forum 185-188 (1995) 985990. 